\title{
Redox Buffer Capacity of the Cell: Theoretical and Experimental Approach
}

\author{
Grigory G. Martinovich • Irina V. Martinovich • \\ Sergey N. Cherenkevich $\cdot$ Heinrich Sauer
}

Published online: 30 July 2010

(C) Springer Science+Business Media, LLC 2010

\begin{abstract}
Reactive oxygen species (ROS) are involved in a variety of biological phenomena, such as mutation, carcinogenesis, inflammation, aging, development, and signal transduction. Intracellular generation of ROS might lead to the activation of redox signaling or oxidative stress. Nonetheless, it is difficult to estimate whether ROS-induced intracellular events are beneficial or deleterious to the cell. The quantitative basis of changes in the intracellular redox state of cells is not well-defined, thus leading to the dilemma that redox changes induced by oxidants in distinct cell types cannot be predicted. To overcome this limitation this study undertakes to analyze on a theoretical as well as on an experimental basis the intracellular redox state changes occurring inside cells upon addition of oxidants or reductants. 2,7-Dichlorodihydrofluorescein $\left(\mathrm{H}_{2} \mathrm{DCF}\right)$ was used to characterize the redox buffer capacity in erythrocytes. It was shown that the redox buffer capacity of erythrocytes in the relation to peroxynitrite $\left(\mathrm{ONOO}^{-}\right)$is 2.1 times lower than the redox buffer capacity of erythrocytes in the relation to hydrogen peroxide $\left(\mathrm{H}_{2} \mathrm{O}_{2}\right)$. The feasibility of redox buffer capacity assessment as an innovative tool for investigation and description of redox signaling events in cells is discussed.
\end{abstract}

Keywords Reactive oxygen species - Redox state Reduction potential - Redox signaling - Oxidative stress . Nernst equation

G. G. Martinovich $(\bowtie) \cdot$ I. V. Martinovich · S. N. Cherenkevich Department of Biophysics, Belarusian State University, Nesavisimosti Ave., 4, 220030 Minsk, Republic of Belarus e-mail: MartinovichGG@bsu.by

H. Sauer

Institute of Physiology, Aulweg 129, 35392 Giessen, Germany

e-mail: heinrich.sauer@physiologie.med.uni-giessen.de

\section{Introduction}

The topic of reactive oxygen species (ROS) continues to receive increasing attention in the scientific community. Recently, it has become apparent that oxidants, in addition to being agents of cytotoxicity, can play important roles in transcriptional regulation, cell proliferation, apoptosis, hormonal signaling, and other fundamental cell functions [1, 2]. The presence of both toxic and beneficial consequences of ROS has led to refinement in the definition of oxidative stress as "an imbalance between oxidants and antioxidants in favor of the oxidants, leading to a disruption of redox signaling and control and/or molecular damage" [3, 4]. Thus, the increase of oxidant concentration in the cell can cause activation of cellular targets and/or molecular damage. The specific result of oxidant action depends on the ratio of oxidants and antioxidants, frequently designated as redox state.

Redox state is a widely used term for the description of redox phenomena in biological systems. The regulating mechanisms responsible for maintaining the redox state are not yet fully known. Previously it has been shown that changes in the redox state may lead to a cascade of intracellular events that are either beneficial or deleterious to the cell [5-7].

There are various methods of redox state description in cells [8-11]. Reduction potentials of different redox couples calculated with the Nernst equation are often used in these methods for quantifying changes in redox state. However, there is an apparent difference concerning the magnitude and direction of the redox changes experienced by the cell during proliferation and contact inhibition of growth. It was shown that the redox potential of distinct couples varies differentially in both magnitude and direction during successive stages of rat IEC-6 intestinal 
epithelial cell growth [12]. This finding points out the difficulty of defining the intracellular redox status at particular stages of cell growth by examining only one redox couple.

The impact of redox variation on the cell or intracellular target must be considered as "effects on the neighborhood" more than effects on a singular factor. In order to consider the contribution of different redox couples in the formation of the intracellular redox state, it was recently proposed by us to use the concept of effective reduction potential [11]. The effective reduction potential $\left(E^{\mathrm{eff}}\right)$ of a redox system is defined by

$E^{\mathrm{eff}}=\sum_{i=1}^{n} a_{i} E_{i}$

where

$a_{i}=\frac{c_{i} z_{i}}{\sum_{j=1}^{n} c_{j} z_{j}}$

is the "specific charge" transferred in a given reaction; $E_{i}$ is the reduction potential of the given redox couple; $c_{i}$ is the molar concentration of reduced species in the given redox couple; and $z_{i}$ is the number of electrons which transfer on oxidized species of a given couple in one redox reaction. The specific charge is equal to the ratio of the charge transferred in a given reaction to total charge transferred in all reactions.

This definition allows considering the "effective reduction potential" as the quantitative parameter of intracellular redox state characterizing the total reductive capacity of the medium. The concentrations of reducing agents in different biological fluids, organelles, and cells vary over a broad range, and this results in different values of the effective reduction potential in biological media [11].

The oxidants in biological systems induce changes in the cell redox state, which can be indicated by the change of effective reduction potential value. Redox regulation will occur under small changes in the effective reduction potential value. Oxidative stress will take place under large changes in the effective reduction potential value. However, the value of effective reduction potential does not allow answering to the question how oxidants will act under definite conditions. In different cell types the same oxidant can result in different cell responses that correspond to different changes of effective reduction potential value. For example, it was shown that hydrogen peroxide $\left(\mathrm{H}_{2} \mathrm{O}_{2}\right)$ increases proliferation in the normal murine mammary gland NmuMG cell line at concentrations ranging from 10 to $200 \mu \mathrm{M}$ [13]. On the other side, $\mathrm{H}_{2} \mathrm{O}_{2}$ at concentrations ranging from 10 to $100 \mu \mathrm{M}$ induces apoptosis in human lung fibroblasts [14].
In this study it is proposed to use the concept of "redox buffer capacity" for the description of the cell's ability to retain specific values of effective reduction potential at given oxidant concentration changes. The aims of this study were: (1) to introduce the theoretical background of redox buffer capacity; (2) to describe the method of redox buffer capacity measurement; and (3) to measure the redox buffer capacity of erythrocytes upon exposure to $\mathrm{H}_{2} \mathrm{O}_{2}$ and $\mathrm{ONOO}^{-}$(SIN-1).

\section{Theory}

Let us examine the medium that contains only one type of redox couple. In this medium the effective reduction potential will be equal to the reduction potential of the given couple $\left(E_{i}\right)$. The redox buffer capacity of the system is numerically equal to the magnitude of change of concentration of an oxidant (or a reductant) added to a solution, which is reduced (or is oxidized), at change of effective reduction potential on unit $(1 \mathrm{~V})$. Thus, the redox buffer capacity $(r)$ can be defined as

$r=\frac{\partial c_{\mathrm{ox}}}{\partial E^{\mathrm{eff}}}$

where $c_{\mathrm{ox}}$ is the concentration of the added oxidant.

The concept "redox buffer" is analogous to the need for the concept "pH buffer" when performing $\mathrm{pH}$ titration. As a $\mathrm{pH}$ buffer that undergoes a $1 \mathrm{H}^{+}$protonation-deprotonation will buffer over a range of $\pm 1 \mathrm{pH}$ unit around its $\mathrm{p} K_{\mathrm{a}}\left(\mathrm{p} K_{\mathrm{a}}\right.$ is the negative decimal logarithm of a dissociation constant of acid), a redox buffer undergoing a $1 \mathrm{e}^{-}$ oxidation-reduction will buffer over a range of \pm 59.1 around its midpoint potential $\left(E_{\mathrm{m}}\right)$.

The least change of $\mathrm{pH}$ at addition of an acid or a base occurs in the range of $\mathrm{p} K_{\mathrm{a}}$. That is, the $\mathrm{pH}$ buffer capacity of the system is maximal at $\mathrm{p} K_{\mathrm{a}}$. Similarly, the redox buffer capacity of the system is maximal at $E_{\mathrm{m}}$.

In the solution that contains the reductant in concentration $c_{\text {red }}$ the effective reduction potential $\left(E_{\mathrm{s}}^{\text {eff }}\right)$ will be equal to the potential of reductant $\left(E_{\mathrm{red}}\right)$. Upon addition of an oxidant to the solution the effective reduction potential of the system according to Eqs. 1 and 2 can be written in the form:

$E^{\mathrm{eff}}=\frac{c_{\mathrm{red}} z_{\mathrm{red}} E_{\mathrm{s}}^{\mathrm{eff}}+c_{\mathrm{ox}} z_{\mathrm{ox}} E_{\mathrm{ox}}}{c_{\mathrm{red}} z_{\mathrm{red}}+c_{\mathrm{ox}} z_{\mathrm{ox}}}$,

where $c_{\text {red }}$ is the concentration of a reductant, $z_{\text {red }}$ is the number of electrons transferred from one molecule of a reductant, $c_{\mathrm{ox}}$ is the concentration of the added oxidant, $z_{\mathrm{ox}}$ is the number of electrons transferred on one molecule of an oxidant, and $E_{\mathrm{ox}}$ is the reduction potential of an oxidant. The dependence $c_{\mathrm{ox}}$ on $E^{\mathrm{eff}}$ is expressed from Eq. 4: 
$c_{\mathrm{ox}}\left(E^{\mathrm{eff}}\right)=\frac{c_{\mathrm{red}} z_{\mathrm{red}}\left(E^{\mathrm{eff}}-E_{\mathrm{s}}^{\mathrm{eff}}\right)}{z_{\mathrm{ox}}\left(E_{\mathrm{ox}}-E^{\mathrm{eff}}\right)}$.

According to the definition (3) a redox buffer capacity of a solution will be:

$r=r\left(E^{\mathrm{eff}}\right)=\frac{\partial c_{\mathrm{ox}}}{\partial E^{\mathrm{eff}}}=\frac{c_{\mathrm{red}} z_{\mathrm{red}}\left(E_{\mathrm{ox}}-E_{\mathrm{s}}^{\mathrm{eff}}\right)}{z_{\mathrm{ox}}\left(E_{\mathrm{ox}}-E^{\mathrm{eff}}\right)^{2}}$.

The equation for redox buffer capacity of a solution $\left(r_{\mathrm{s}}\right)$ before addition of an oxidant is obtained from Eq. 6 under the assumption that $c_{\mathrm{ox}}=0$. According to Eq. 4 at this condition $E^{\text {eff }}$ is equal to $E_{\mathrm{s}}^{\text {eff }}$, then

$r_{\mathrm{s}}=\frac{c_{\mathrm{red}} z_{\mathrm{red}}}{z_{\mathrm{ox}}\left(E_{\mathrm{ox}}-E_{\mathrm{s}}^{\mathrm{eff}}\right)}$.

Similarly it is possible to derive the equation for redox buffer capacity of a solution in the relation to a reductant:

$r_{\mathrm{s}}=\frac{c_{\mathrm{ox}} z_{\mathrm{ox}}}{z_{\mathrm{red}}\left(E_{\mathrm{s}}^{\text {eff }}-E_{\mathrm{red}}\right)}$,

where $E_{\text {red }}$ is the reduction potential of a reductant.

In a solution that contains two various reductants in the concentrations $c_{1}$ and $c_{2}$ the effective reduction potential is equal to

$E_{\mathrm{s}}^{\mathrm{eff}}=\frac{c_{1} z_{1} E_{1}+c_{2} z_{2} E_{2}}{c_{1} z_{1}+c_{2} z_{2}}$.

The redox buffer capacity of this solution is equal to

$r_{\mathrm{s}}=\frac{c_{1} z_{1}+c_{2} z_{2}}{z_{\mathrm{ox}}\left(E_{\mathrm{ox}}-E_{\mathrm{s}}^{\mathrm{eff}}\right)}$.

The redox buffer capacity of a solution containing reductants in the concentration $c_{1}, c_{2}, \ldots, c_{k}$ will be defined by equations:

$r_{\mathrm{s}}=\frac{\sum_{i=1}^{n} c_{i} z_{i}}{z_{\mathrm{ox}} \cdot\left(E_{\mathrm{ox}}-E_{\mathrm{s}}^{\mathrm{eff}}\right)}$,

$\frac{1}{r_{\mathrm{s}}}=\sum_{i=1}^{n}\left(a_{i}^{2} \cdot \frac{1}{r_{i}}\right)$,

where $r_{i}$ is the redox buffer capacity of $i$-th reductant, which is defined by equation

$r_{i}=\frac{c_{i} z_{i}}{z_{\mathrm{ox}}\left(E_{\mathrm{ox}}-E_{i}\right)}$,

$a_{i}$ is defined by Eq. 2 .

The values of redox buffer capacity calculated for various cell reductants in the relation to $\mathrm{H}_{2} \mathrm{O}_{2}$ and $\mathrm{ONOO}^{-}$are presented in Table 1.

As shown in Table 1 the redox buffer capacity depends on the type of a reductant and the type of an oxidant. The lesser the difference between reduction potentials of a reductant and an oxidant (a difference in the free energy),
Table 1 Redox buffer capacity of cell reductants

\begin{tabular}{llll}
\hline $\begin{array}{l}\text { Type and } \\
\begin{array}{l}\text { concentration } \\
\text { of the reductant }\end{array}\end{array}$ & $\begin{array}{l}E_{\mathrm{m}}, \mathrm{mV} \\
\mathrm{pH} \mathrm{7.0)}\end{array}$ & $\begin{array}{l}r \text { to } \mathrm{H}_{2} \mathrm{O}_{2}^{\mathrm{a}}, \\
\mathrm{mM} / \mathrm{V} \\
(\mathrm{pH} \mathrm{7.0)}\end{array}$ & $\begin{array}{l}r \text { to } \mathrm{ONOO}^{-\mathrm{b}}, \\
\mathrm{mM} / \mathrm{V}(\mathrm{pH} \mathrm{7.0})\end{array}$ \\
\hline $\mathrm{NADPH}, 10 \mathrm{mM}$ & -320 & 16.1 & 6.6 \\
$\mathrm{GSH}, 10 \mathrm{mM}$ & -240 & 18.5 & 6.9 \\
$\mathrm{AscH}, 10 \mathrm{mM}$ & +58 & 41.3 & 8.8 \\
\hline
\end{tabular}

${ }^{\mathrm{a}}$ For $\mathrm{H}_{2} \mathrm{O}_{2}$, the $E_{\mathrm{m}}=300 \mathrm{mV}(z=2)(\mathrm{pH} 7.0)$ is used [15]

b For $\mathrm{ONOO}^{-}$, the $E_{\mathrm{m}}=1200 \mathrm{mV}(z=2)(\mathrm{pH} 7.0)$ is used [16]

Table 2 Intracellular redox buffer capacities

\begin{tabular}{lll}
\hline Type of cell & $\begin{array}{l}r \text { to } \mathrm{H}_{2} \mathrm{O}_{2}, \\
\mathrm{mM} / \mathrm{V} \\
(\mathrm{pH} 7.0)\end{array}$ & $\begin{array}{l}r \text { to } \mathrm{ONOO}^{-}, \\
\mathrm{mM} / \mathrm{V} \\
(\mathrm{pH} 7.0)\end{array}$ \\
\hline Rat $\beta$-cell cytoplasm & 17.0 & 4.5 \\
Human monocyte cytoplasm & 21.5 & 5.7 \\
Human neuron cytoplasm & 22.0 & 6.0 \\
Rat hepatocyte cytoplasm & 16.0 & 5.7 \\
Human astrocyte cytoplasm & 17.2 & 6.3 \\
Human erythrocyte cytoplasm & 4.7 & 1.7 \\
\hline
\end{tabular}

the greater the redox buffer capacity of a reductant in relation to the given oxidant.

The cell redox buffer capacity depends on the type and concentration of reductants which are contained inside the cell. Differences in redox buffer capacities are the consequence of existing differences in the values of tissuereductant concentrations. The values of redox buffer capacities in different cells estimated by Eq. 11 are presented in Table 2. The redox buffer capacities were calculated with the use of mean concentrations of basic reducing agents (from [11]) and values of its reduction potentials at $\mathrm{pH}$ 7.0.

Our results show that the greatest value of effective reductive potential [11] does not necessarily correspond to the greatest redox buffer capacity of the respective system. The redox buffer capacity of the system is not exclusively the sum of reductant concentrations. Depending on the specific set of reductant some cell species more effectively resist an oxidation caused by $\mathrm{H}_{2} \mathrm{O}_{2}$ (they have the higher value of redox buffer capacity in relation to $\mathrm{H}_{2} \mathrm{O}_{2}$, for example, neurons), others more effectively resist an oxidation induced by $\mathrm{ONOO}^{-}$(they have the higher value of redox buffer capacity in relation to $\mathrm{ONOO}^{-}$, for example, astrocytes).

The changes of effective reduction potential $\left(\Delta E^{\mathrm{eff}}\right)$ in erythrocytes as function of oxidant concentration are presented in Fig. 1. The changes in $\Delta E^{\text {eff }}$ with an increase in the $\mathrm{H}_{2} \mathrm{O}_{2}$ and $\mathrm{ONOO}^{-}$concentration, respectively, are estimated by using Eq. 1. 


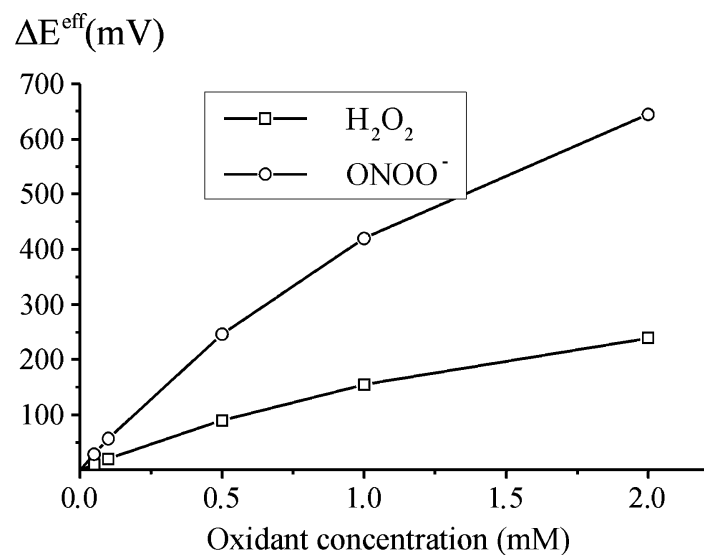

Fig. 1 The changes of effective reduction potential in erythrocytes as function of oxidant concentration

These results demonstrate that changes in the redox state of erythrocytes following an addition of $\mathrm{ONOO}^{-}$occur considerably more rapidly than following the addition of $\mathrm{H}_{2} \mathrm{O}_{2}$. That is, the changes in $\Delta E^{\text {eff }}$ depend on the redox buffer capacity toward the oxidant. The changes in cell redox state reflected by the value of effective reduction potential occur more slowly at the greater redox buffer capacity.

The introduced concept of redox buffer capacity allows comparing the antioxidant activity of different biological media and cell types during an oxidant action. The knowledge of the redox buffer capacity value makes it possible to predict the direction and value of change of the effective reduction potential (see [11]).

During the practical application of these redox parameters for quantitative description of cellular redox state, it is sufficient to consider the contribution of redox molecules with the highest concentrations inside the cells. However, the determination of the concentrations of such cellular redox molecules with the use of high performance liquid chromatography is a time- and labor-consuming process that limits the wide practical use of the indicated parameters in clinical diagnostics and scientific research. Therefore, we undertook in this study to develop a method of determination of cellular (erythrocyte) redox parameters by applying a microfluorometric analysis procedure which is easy to perform and can be used for routine screenings of the intracellular redox state in specific cell species.

The value of effective redox potential characterizes the electron donor and electron acceptor properties of intracellular medium, and its change can be registered with the use of the specific redox sensors. In this study the fluorescent probe $2^{\prime}, 7^{\prime}$-dichlorodihydrofluorescein $\left(\mathrm{H}_{2} \mathrm{DCF}\right)$ was used as redox sensor.

\section{Materials and Methods}

Blood and Solutions

Freshly drawn blood from healthy human donors was used for the experiments. The erythrocytes were washed three times by centrifugation $(1500 \times g, 8 \mathrm{~min})$ at room temperature in phosphate buffered saline (PBS), pH 7.4. Plasma and buffy coat were removed by aspiration.

The PBS used throughout all experiments consisted of (in $\mathrm{mM}$ ): $137 \mathrm{NaCl}, 2.7 \mathrm{KCl}, 8 \mathrm{Na}_{2} \mathrm{HPO}_{4}$ and $1.5 \mathrm{KH}_{2} \mathrm{PO}_{4}$, pH 7.4.

3-Morpholinosydnonimine (SIN-1) (Sigma, USA) is used as $\mathrm{ONOO}^{-}$donor. $\mathrm{ONOO}^{-}$is considered an endogenously formed cytotoxic factor derived from nitric oxide (NO) and superoxide anion $\left(\dot{\mathrm{O}}_{2}^{-}\right)[17,18]$. SIN-1 is the metabolite form of molsidomine, which exerts vasodilative effects. It decomposes spontaneously in neutral aqueous media consuming oxygen to release (NO) and $\left(\dot{\mathrm{O}}_{2}^{-}\right)$ simultaneously [19]. Thus, the reagent can be used as an effective $\mathrm{ONOO}^{-}$donor.

\section{Measurement of Redox State Parameters}

The intracellular redox state parameters were investigated using the fluorescent dye $2^{\prime}, 7^{\prime}$-dichlorodihydrofluorescein diacetate $\left(\mathrm{H}_{2}\right.$ DCF-DA) (Sigma, USA) which is a nonpolar compound that is converted into a nonfluorescent polar derivative $\left(\mathrm{H}_{2} \mathrm{DCF}\right)$ by cellular esterases after incorporation into cells. The membrane-impermeable $\mathrm{H}_{2} \mathrm{DCF}$ is rapidly oxidized to the highly fluorescent $2^{\prime}, 7^{\prime}$-dichlorofluorescein (DCF) in the presence of intracellular ROS [20]. The rate of $\mathrm{H}_{2} \mathrm{DCF}$ oxidation depends on both the intracellular oxidant concentration [21] and on the intracellular reductant concentration [22].

Erythrocytes were incubated for 30 min with $10 \mu \mathrm{M}$ $\mathrm{H}_{2}$ DCF-DA (dissolved in dimethylsulfoxide) in PBS at $37^{\circ} \mathrm{C}$. After loading, the erythrocytes were rinsed two times in PBS and the DCF fluorescence intensity was measured using $488 \mathrm{~nm}$ excitation/530 $\mathrm{nm}$ emission settings (Spectrofluorometer LSF 1211A, Solar, Republic of Belarus). All experiments were carried out at $37^{\circ} \mathrm{C}$.

\section{Statistical Treatment of the Results}

Values are given as means of at least three independent experiments carried out on blood of different donors \pm SD. Where errors are not shown they were smaller than symbols. Where necessary, a paired $t$-test was used to determine the significance of the difference between values. The values were taken as significantly different when $P<0.05$. 


\section{Results and Discussion}

It was previously demonstrated that $\mathrm{H}_{2} \mathrm{DCF}$ can be used as detector of a broad range of intracellular oxidizing reactions [23]. This study tests the hypothesis that $\mathrm{H}_{2} \mathrm{DCF}$ may be used as sensor of changes in integral redox state parameters.

Effective redox potential and redox buffer capacity characterize a steady redox state. In a steady redox state the concentrations of basic redox agents are invariable. The transition from one steady redox state to another occurs after introduction of oxidant into the system. In experimental conditions the concentration of DCF will be changed under transition between steady redox states. The concentration of oxidized $\mathrm{H}_{2} \mathrm{DCF}$ depends on both the intracellular oxidant concentration and on the intracellular reductant concentration. Molecules of oxidants can interact with molecules of $\mathrm{H}_{2} \mathrm{DCF}$ or molecules of reductants. The increase of reductant concentration will decrease the concentration of DCF that formed in transition between steady redox states.

It should be noted that cells contain different antioxidant enzymes. The function of an enzyme is to increase the rate of a reaction. Enzymes do not affect reaction equilibria. That is in cells enzymes increase a rate transition between the steady redox states but not influence on a total amount of electrons transferred in reactions.

In a first approximation the amount of DCF molecules is actually proportional to the amount of electrons $\left(Q_{\text {ox }}\right)$ that transfer from $\mathrm{H}_{2} \mathrm{DCF}$ molecules on oxidants molecules. On the other hand, the amount of $\mathrm{H}_{2} \mathrm{DCF}$ molecules is proportional to the amount of electrons $\left(Q_{\text {red }}\right)$ that transfer from reductant molecules on oxidant molecules. These suggestions can be written mathematically by the next equations

$[\mathrm{DCF}]=k Q_{\mathrm{ox}}=k z_{\mathrm{ox}} c_{\mathrm{ox}}$,

$\left[\mathrm{H}_{2} \mathrm{DCF}\right]=k Q_{\mathrm{red}}=k \sum_{i=1}^{n} z_{i} c_{i}$.

From (14) and (15), the redox state of $\mathrm{H}_{2} \mathrm{DCF}$ is described by ratio:

$\frac{[\mathrm{DCF}]}{\left[\mathrm{H}_{2} \mathrm{DCF}\right]}=\frac{z_{\mathrm{ox}} c_{\mathrm{ox}}}{\sum_{i=1}^{n} z_{i} c_{i}}$.

If total intracellular concentration of dye is constant (during time of registration)

$[\mathrm{DCF}]+\left[\mathrm{H}_{2} \mathrm{DCF}\right]=C_{0}=\mathrm{const}$,

then Eq. 16 can be written as

$\frac{[\mathrm{DCF}]}{C_{0}-[\mathrm{DCF}]}=\frac{z_{\mathrm{ox}} c_{\mathrm{ox}}}{\sum_{i=1}^{n} z_{i} c_{i}}$.

After transition between steady redox states, the changes of DCF concentration will be equal to
$[\mathrm{DCF}]=C_{0} \frac{1}{1+\frac{\sum_{i=1}^{n} z_{i} c_{i}}{z_{\mathrm{ox}} c_{\mathrm{ox}}}}$.

The incubation of $\mathrm{H}_{2}$ DCF-loaded erythrocytes with $\mathrm{H}_{2} \mathrm{O}_{2}$ and SIN-1 resulted in a dose-dependent increase in DCF fluorescence intensity (Figs. 2, 3). The results illustrated in Figs. 2 and 3 indicate that the rates of $\mathrm{H}_{2}$ DCF oxidation in erythrocytes during the incubation with $\mathrm{H}_{2} \mathrm{O}_{2}$ and SIN-1 are considerably distinguished. Figure 2 shows that the rate of $\mathrm{H}_{2} \mathrm{DCF}$ oxidation in cells is declining during exposure to $\mathrm{H}_{2} \mathrm{O}_{2}$. The observed reduction in the rate of oxidation by $\mathrm{H}_{2} \mathrm{O}_{2}$ is related to the decrease of $\mathrm{H}_{2} \mathrm{O}_{2}$ concentration as a result of its consumption by antioxidant systems [21].

Figure 3 shows that the increase in DCF fluorescence intensity started after some delay during the incubation with SIN-1. This observation may be explained on the basis of the mechanism of decomposition of SIN-1. The time course of the decomposition of SIN-1 was previously investigated [24]. It was nonlinear, and some delay occurred because of hydrolysis of the compound.

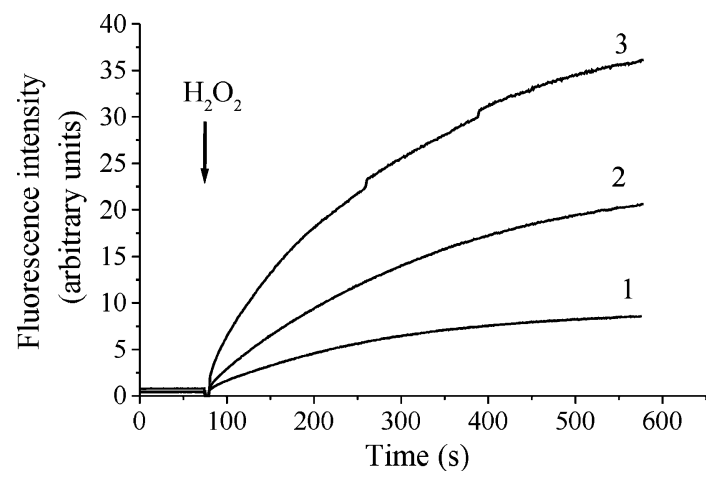

Fig. 2 The effects of $\mathrm{H}_{2} \mathrm{O}_{2}$ on the DCF fluorescence intensity in $\mathrm{H}_{2}$ DCF-loaded erythrocytes $\left(5 \times 10^{6}\right.$ cell $\left./ \mathrm{ml}\right) .10 .1 \mathrm{mM} \mathrm{H}_{2} \mathrm{O}_{2}$ was added. $20.25 \mathrm{mM} \mathrm{H}_{2} \mathrm{O}_{2}$ was added. $30.5 \mathrm{mM} \mathrm{H} \mathrm{H}_{2} \mathrm{O}_{2}$ was added

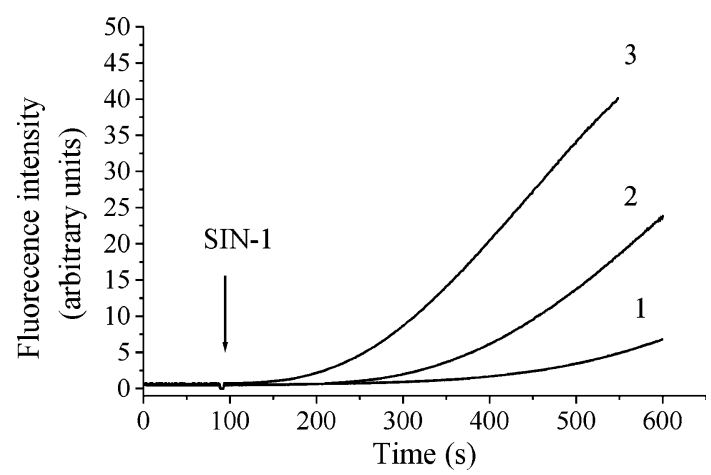

Fig. 3 The effects of SIN-1 on the DCF fluorescence intensity in $\mathrm{H}_{2}$ DCF-loaded erythrocytes $\left(5 \times 10^{6}\right.$ cell $\left./ \mathrm{ml}\right) .10 .05 \mathrm{mM} \mathrm{SIN}-1$ was added. $20.1 \mathrm{mM}$ SIN-1 was added. $30.25 \mathrm{mM}$ SIN-1 was added 
Our results indicated that the $\mathrm{H}_{2} \mathrm{DCF}$ oxidation rate depends on the oxidant concentration. Based on the results reported here, the analysis of the rate of $\mathrm{H}_{2} \mathrm{DCF}$ oxidation was used to determine the parameters of the redox state.

In steady redox state the oxidant concentration is constant. Thus, in steady redox state the rate of $\mathrm{H}_{2} \mathrm{DCF}$ oxidation must be constant. In our experimental conditions the transition cells in new steady redox state will take place approximately through $300 \mathrm{~s}$ after the addition of oxidant. According to aforesaid assumptions, the next fluorescent index can be used for determination of redox state parameters

$V_{\mathrm{f}}=\frac{I_{300}}{300} \sim \frac{1}{1+\frac{\sum_{i=1}^{n} z_{i} c_{i}}{z_{\mathrm{ox}} c_{\mathrm{ox}}}}$.

Basic difficulty in the experimental determination of redox state parameters lies in the fact that the effective redox potential is changed after introduction of oxidant into the system, and therefore, the redox buffer capacity is likewise changed. Thus, it is necessary to determine the dependence of effective redox potential and redox buffer capacity on the concentration of oxidant added to the system.

According to Eq. 1 a change of oxidant concentration within the system will cause a shift in the initial value of effective reduction potential $\left(E^{\text {eff }}\right)$. Let us consider the solution in which the reductant concentration is equal to $c_{\text {red }}$. After addition of an oxidant to the solution, the effective redox potential of system will change to the value:

$E^{\mathrm{eff}}+\Delta E^{\mathrm{eff}}=\frac{c_{\mathrm{red}} z_{\mathrm{red}} E^{\mathrm{eff}}+c_{\mathrm{ox}} z_{\mathrm{ox}} E_{\mathrm{ox}}}{c_{\mathrm{red}} z_{\mathrm{red}}+c_{\mathrm{ox}} z_{\mathrm{ox}}}$

Let us find an increment of effective reduction potential $\left(\Delta E^{\text {eff }}\right)$ using Eq. 21:

$\Delta E^{\mathrm{eff}}=\frac{c_{\mathrm{red}} z_{\mathrm{red}} \cdot E^{\mathrm{eff}}+c_{\mathrm{ox}} z_{\mathrm{ox}} \cdot E_{\mathrm{ox}}}{c_{\mathrm{red}} z_{\mathrm{red}}+c_{\mathrm{ox}} z_{\mathrm{ox}}}-E^{\mathrm{eff}}$,

$\Delta E^{\mathrm{eff}}=\frac{c_{\mathrm{ox}} z_{\mathrm{ox}} \cdot\left(E_{\mathrm{ox}}-E^{\mathrm{eff}}\right)}{c_{\mathrm{red}} z_{\mathrm{red}}+c_{\mathrm{ox}} z_{\mathrm{ox}}}$

In the case of the multicomponent medium that contains $k$ reductants in the concentration $c_{1}, c_{2}, \ldots, c_{k}, \Delta E^{\text {eff }}$ can be written as

$\Delta E^{\mathrm{eff}}=\frac{c_{\mathrm{ox}} z_{\mathrm{ox}} \cdot\left(E_{\mathrm{ox}}-E^{\mathrm{eff}}\right)}{c_{\mathrm{ox}} z_{\mathrm{ox}}+\sum_{i=1}^{k} c_{i} z_{i}}$

Let us introduce the following designations:

$\Delta E_{\max }^{\mathrm{eff}}=E_{\mathrm{ox}}-E^{\mathrm{eff}} \quad$ and $\quad k_{\mathrm{cap}}=\frac{\sum_{i=1}^{k} c_{i} z_{i}}{z_{\mathrm{ox}}}$.

Then equation (24) can be written in the form:

$\Delta E^{\mathrm{eff}}=\frac{\Delta E_{\mathrm{max}}^{\mathrm{eff}}}{1+k_{\mathrm{cap}} / c_{\mathrm{ox}}}$. where $\Delta E_{\max }^{\mathrm{eff}}$ is the maximal change of effective reduction potential that is possible at condition $c_{\mathrm{ox}} \gg c_{\text {red }}$. The constant $k_{\text {cap }}$ has the dimension of concentration.

It is also evident from Eq. 26 that with $k_{\mathrm{cap}}=c_{\mathrm{ox}}$, change in the value of the effective reduction potential is equal to $\Delta E_{\max }^{\mathrm{eff}} / 2$. Thus, constant $k_{\text {cap }}$ is numerically equal to the oxidant concentration that changes the value of effective reduction potential to half of its maximum value. Equation 26 in the opposite coordinates (Fig. 4) is the equation of straight line with the inclination $k_{\mathrm{cap}} / \Delta E_{\max }^{\mathrm{eff}}$ and the intersections: along the $Y$-axis at point $1 / \Delta E_{\max }^{\text {eff }}$ and along the $X$-axis at the point $-1 / k_{\text {cap }}$

$\frac{1}{\Delta E^{\mathrm{eff}}}=\frac{1}{\Delta E_{\max }^{\mathrm{eff}}}+\frac{k_{\mathrm{cap}}}{\Delta E_{\max }^{\mathrm{eff}}} \frac{1}{c_{\mathrm{ox}}}$.

According to Eqs. 11 and 25 the redox buffer capacity can be described as the tangent of slope angle of the plot presented in Eq. 27.

On other hand, from Eqs. 20, 25, and 26

$V_{\mathrm{f}}=k_{0} \Delta E^{\mathrm{eff}}$

The theoretical consequence (28) has been experimentally established. The dependencies of $\mathrm{H}_{2} \mathrm{DCF}$ oxidation rate $\left(V_{\mathrm{f}}\right)$ in erythrocytes on the oxidant concentration are shown in Fig. 5. The graphic form of this dependence is similar to the theoretically calculated dependence of $\Delta E^{\text {eff }}$ on the oxidant concentration (Fig. 1). The dependencies of $\Delta E^{\mathrm{eff}}$ and $V_{\mathrm{f}}$ on $\mathrm{H}_{2} \mathrm{O}_{2}$ concentration are shown in Fig. 6. According to these data, the ratio of the values of function $V_{\mathrm{f}}\left(\left[\mathrm{H}_{2} \mathrm{O}_{2}\right]\right)$ to the values function $\Delta E^{\text {eff }}\left(\left[\mathrm{H}_{2} \mathrm{O}_{2}\right]\right)$ with identical values of argument is constant (Fig. 6, inset).

Thus, the above findings lead to the important conclusion that redox buffer capacity and the effective reduction potential can be determined with the analysis of the dependence of $1 / V_{\mathrm{f}}$ on $1 / c_{\mathrm{ox}}$ built on the basis of experimental data. The dependence of $1 / V_{\mathrm{f}}$ on $1 / c_{\text {ox }}$ obtained on the base of the experimental data is used for determining the redox buffer capacity and effective reduction potential

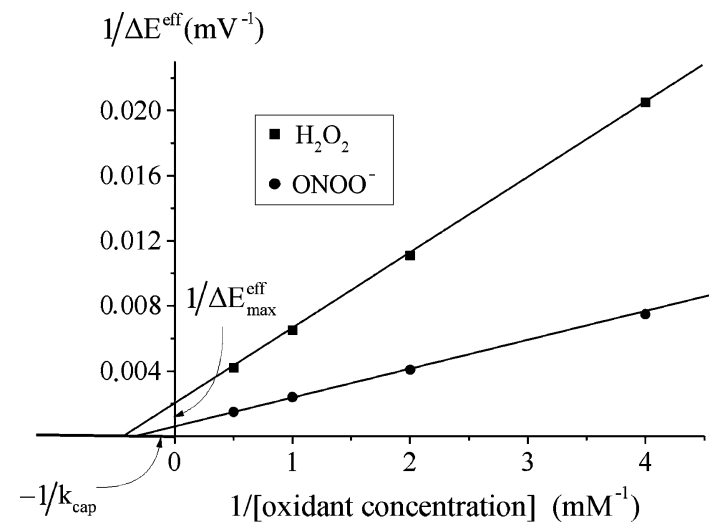

Fig. 4 The determination of redox parameters on the basis of Eq. 22 


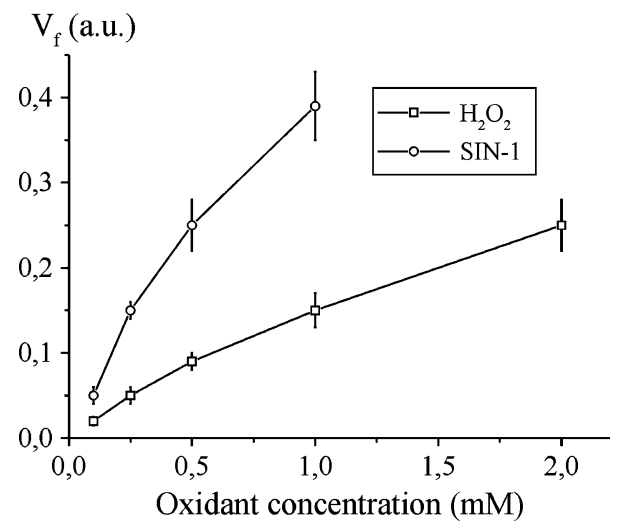

Fig. 5 The dependence of $\mathrm{H}_{2} \mathrm{DCF}$ oxidation rate in erythrocytes on the oxidant concentration

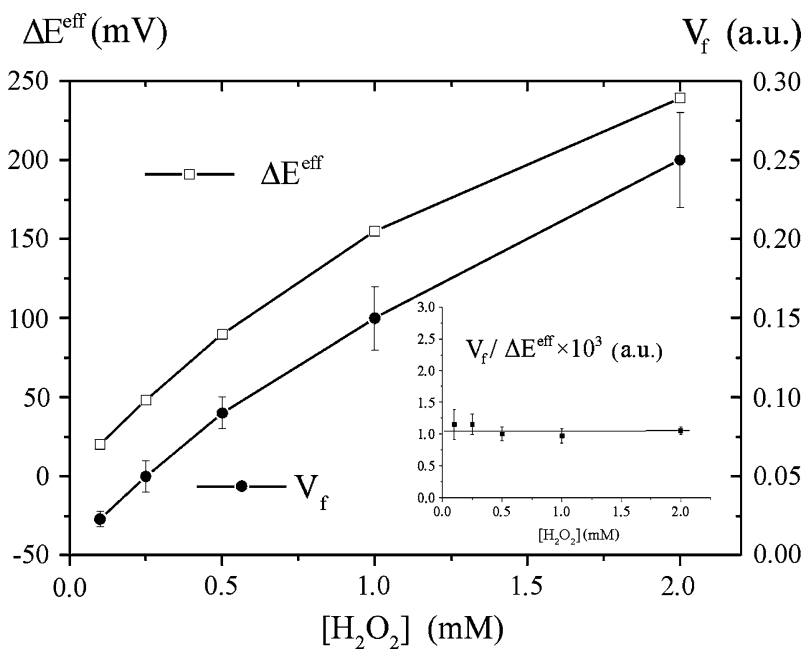

Fig. 6 The dependence of $\mathrm{H}_{2} \mathrm{DCF}$ oxidation rate and $\Delta E^{\text {eff }}$ in erythrocytes on the $\mathrm{H}_{2} \mathrm{O}_{2}$ concentration

of erythrocytes (Fig. 7). The value of redox buffer capacity of erythrocytes in relation to $\mathrm{H}_{2} \mathrm{O}_{2}$ obtained with the method described above is $4.2 \pm 0.5$ a.u. The value of redox buffer capacity of erythrocytes in the relation to SIN1 is $2.0 \pm 0.5$ a.u. That is, the redox buffer capacity of erythrocytes in relation to SIN-1 is 2.1 times lower than the redox buffer capacity of erythrocytes in relation to $\mathrm{H}_{2} \mathrm{O}_{2}$. Theoretically estimated, the redox buffer capacity of erythrocytes in the relation to $\mathrm{ONOO}^{-}$is 2.8 times lower than the redox buffer capacity of erythrocytes in relation to $\mathrm{H}_{2} \mathrm{O}_{2}$ (see Table 2). Thus, theoretical and experimental studies lead to similar results.

The developed "redox titration" method makes it possible to determine the redox state parameters of different types of cells, and also the redox state parameters of cells with different functional activities.

From a thermodynamic point of view, a cell is not in equilibrium with the environment. Instead cell supports a nonequilibrium steady redox state that is indicated by the

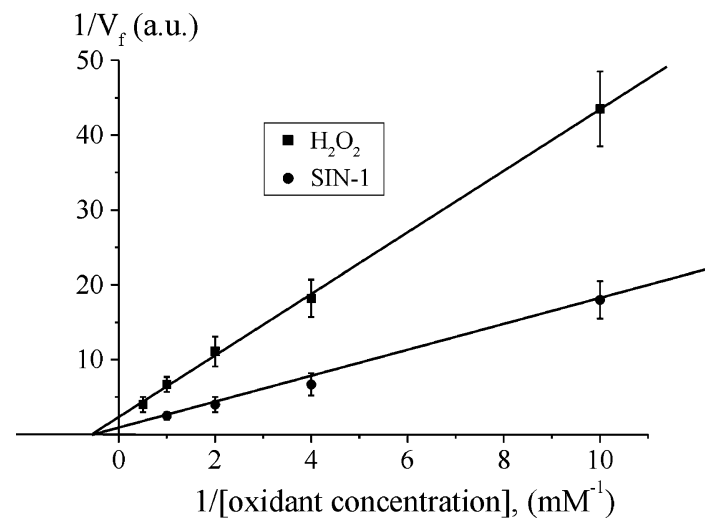

Fig. 7 Determination of the redox parameters on the basis of the experimental values

different experimental approaches. The reduction potential of the GSSG/2GSH couple calculated with the Nernst equation is used most often for the quantitative description of redox state $[8,25,26]$. The magnitude of the cellular redox state parameters may determine whether a cell will proliferate, differentiate, or die [5, 7, 27-30].

Changes in redox state may regulate the oxidation or reduction of protein thiol groups that will be accompanied by the conformation alteration of these proteins and, thus, modulate their functions $[31,32]$. Protein thiols are often described as "sulfur switches" that provide a means to control a broad range of activity and structure of proteins [8]. Changes in the redox state of thiol/disulfide couples affect enzyme activity, protein conformation, transporter activity, ligand binding to receptors, and other protein functions [33-35]. However, there is increasing evidence that the major thiol/disulfide couples are not at equilibrium in biological systems $[10,26]$. Hence, the concentrations of reduced or oxidized protein thiols may be independent of the reduction potential of the GSSG/2GSH couple, which implies that the mechanisms of oxidation of regulatory protein thiol still need to be elucidated. The road to understand the oxidant and antioxidant actions can, therefore, not be focused only on one redox couple but needs to consider all redox players and their interactions inside the cell.

The steady redox state is formed as a result of interaction of many redox couples. Changes of redox state of these couples not necessarily induce changes in reduction potential of the GSSG/2GSH couple. Recently, it has been demonstrated that the ROS generated from spermine NONOate in human endothelial cells decreased intracellular ascorbate concentrations, although reduced glutathione was not affected [36]. It was also shown that nitrogen dioxide depletes uric acid and ascorbic acid but not glutathione in respiratory tract lining fluid [37]. Moreover, the GSSG/2GSH couple in biological fluids, organelles, cells or tissues is not always represented by a basic redox couple 
in the medium. Quantitative analysis of ascorbate and glutathione contents in developing rat cortex and hippocampus studies revealed that ascorbate predominates in neurons, whereas glutathione is predominant in glia [38]. Glutathione concentration in blood plasma is much lesser than concentration of uric and ascorbic acid [39]. Therefore, a new fundamental approach taking into account the contribution of different redox couples in the formation of the redox state within cells is required to describe quantitatively the redox environment in different media.

In this article the redox buffer capacity and effective reduction potential concepts have been used for the description of changes in erythrocyte redox state as a "model cell" representing the general applicability of our method. The proposed approach shows new possibilities for the description of cellular redox mechanisms. The use of the redox buffer capacity and effective reduction potential concepts allows interpreting a variety of intracellular and extracellular redox signaling phenomena. However, the magnitude of effective redox potential does not admit to describe how the redox state within cells will change under increase of the oxidant concentration. The redox buffer capacity determines how the value of effective redox potential will change under defined conditions. It explains why cells with different redox buffer capacity will react quite different to similar oxidants. For example, monocytes display a higher redox buffer capacity in relation to $\mathrm{H}_{2} \mathrm{O}_{2}$ than erythrocytes (see Table 2). Therefore, in monocytes the shift of the $E^{\text {eff }}$ value induced by $0.1 \mathrm{mM} \mathrm{H}_{2} \mathrm{O}_{2}$ is $4.5 \mathrm{mV}$ as compared to erythrocytes, where the shift of the $E^{\text {eff }}$ value induced by $0.1 \mathrm{mM} \mathrm{H}_{2} \mathrm{O}_{2}$ is $21.5 \mathrm{mV}$. Perhaps, $0.1 \mathrm{mM}$ $\mathrm{H}_{2} \mathrm{O}_{2}$ can activate redox signaling mechanisms in monocytes, but induces oxidative stress in erythrocytes.

In summary the data of this study theoretically and experimentally support the notion that the redox buffer capacity represents the result of cumulative and synergetic interactions of many redox species. These redox species represent an integrating parameter more than displaying the simple sum of measurable reductant concentrations. The more accurate definition of protein redox potentials and medium redox parameters described in our study permits to foresee the cellular processes to be activated or inactivated at distinct cellular redox states.

Acknowledgments This study was supported in part by the Belarusian Republican Foundation for Fundamental Research (Grant B08-056 and Grant B09-067).

\section{References}

1. Sauer, H., Wartenberg, M., \& Hescheler, J. (2001). Reactive oxygen species as intracellular messengers during cell growth and differentiation. Cellular Physiology and Biochemistry, 11, 173-186.

2. Droge, W. (2002). Free radicals in the physiological control of cell function. Physiological Reviews, 82, 47-95.

3. Jones, D. P. (2006). Redefining oxidative stress. Antioxidants \& Redox Signaling, 8, 1865-1879.

4. Sies, H., \& Jones, D. P. (2007). Oxidative stress. San Diego: Elsevier.

5. Kirlin, W., Cai, J., Thompson, S., Diaz, D., Kavanagh, T., \& Jones, D. (1999). Glutathione redox potential in response to differentiation and enzyme inducers. Free Radical Biology and Medicine, 27, 1208-1218.

6. Smith, J., Ladi, E., Mayer-Proschel, M., \& Noble, M. (2000). Redox state is a central precursor cell modulator of the balance between self-renewal and differentiation in a dividing glial. Proceedings of the National Academy of Sciences of the United States of America, 97, 10032-10037.

7. Kranner, I., Birtic, S., Anderson, K. M., \& Pritchard, H. W. (2006). Glutathione half-cell reduction potential: A universal stress marker and modulator of programmed cell death? Free Radical Biology and Medicine, 40, 2155-2165.

8. Schafer, F. Q., \& Buettner, G. R. (2001). Redox environment of the cell as viewed through the redox state of the glutathione disulfide/glutathione couple. Free Radical Biology and Medicine, 30, 1191-1212.

9. Hancock, J. T., Desikan, R., Neill, S. J., \& Cross, A. R. (2004). New equations for redox and nano-signal transduction. Journal of Theoretical Biology, 226, 65-68.

10. Jones, D. P., Go, Y. M., Anderson, C. L., Ziegler, T. R., Kinkade, J. M., \& Kirlin, W. G. (2004). Cysteine/cystine couple is a newly recognized node in the circuitry for biologic redox signaling and control. FASEB Journal, 18, 1246-1248.

11. Martinovich, G. G., Cherenkevich, S. N., \& Sauer, H. (2005). Intracellular redox state: Towards quantitative description. European Biophysics Journal, 34, 937-942.

12. Attene-Ramos, M., Kitiphongspattana, K., Ishii-Schrade, K., \& Gaskins, H. (2005). Temporal changes of multiple redox couples from proliferation to growth arrest in IEC-6 intestinal epithelial cells. American Journal of Physiology. Cell Physiology, 289, C1220-C1228.

13. Galli, S., Labato, M. I., Bal de Kier Joffe, E., Carreras, M. C., \& Poderoso, J. J. (2003). Decreased mitochondrial nitric oxide synthase activity and hydrogen peroxide relate persistent tumoral proliferation to embryonic behavior. Cancer Research, 63, 6370-6377.

14. Teramoto, S., Tomita, T., Matsui, H., Ohga, E., Matsuse, T., \& Ouchi, Y. (1999). Hydrogen peroxide-induced apoptosis and necrosis in human lung fibroblasts: Protective roles of glutathione. Japanese Journal of Pharmacology, 79, 33-40.

15. Koppenol, W. H., \& Butler, J. (1985). Energetics of interconversion reactions of oxyradicals. Free Radical Biology and Medicine, 1, 91-131.

16. Koppenol, W. H., Moreno, J. J., Pryor, W. A., Ischiropoulos, H., \& Beckman, J. S. (1992). Peroxynitrite, a cloaked oxidant formed by nitric oxide and superoxide. Chemical Research in Toxicology, 5, 834-842.

17. Pryor, W. A., \& Squadrito, G. L. (1995). The chemistry of peroxynitrite: A product from the reaction of nitric oxide with superoxide. American Journal of Physiology, 268, L699-L722.

18. Radi, R., Peluffo, G., Alvarez, M., Navaliat, M., \& Cayota, A. (2001). Unraveling peroxynitrite formation in biological system. Free Radical Biology and Medicine, 30, 463-488.

19. Feelisch, M., Ostrowski, J., \& Noack, E. (1989). On the mechanism of NO release from sydnonimines. Journal of Cardiovascular Pharmacology, 14, S13-S22. 
20. LeBel, C. P., Ischiropoulos, H., \& Bondy, S. C. (1992). Evaluation of the probe $2^{\prime}, 7^{\prime}$-dichlorofluorescin as an indicator of reactive oxygen species formation and oxidative stress. Chemical Research in Toxicology, 5, 227-231.

21. Martinovich, G. G., \& Cherenkevich, S. N. (2005). Consumption of intracellular hydrogen peroxide in epithelial human amnion cells (in Russ). Biomeditsinskaia khimiia, 51, 626-633.

22. Jakubowski, W., \& Bartosz, G. (2000). 2,7-Dichlorofluorescin oxidation and reactive oxygen species: What does it measure? Cell Biology International, 24, 757-760.

23. Hempel, S. L., Buettner, G. R., O’Malley, Y. Q., Wessels, D. A., \& Flaherty, D. M. (1999). Dihydrofluorescein diacetate is superior for detecting intracellular oxidants: comparison with $2^{\prime}, 7^{\prime}$-dichlorodihydrofluorescein diacetate, 5(and 6)-carboxy-2',7'-dichlorodihydrofluorescein diacetate, and dihydrorhodamine 123. Free Radical Biology and Medicine, 27, 146-159.

24. Bohn, H., \& Schonafinger, K. (1989). Oxygen and oxidation promote the release of nitric oxide from sydnonimines. Journal of Cardiovascular Pharmacology, 14, S6-S12.

25. Jones, D. P. (2002). Redox potential of GSH/GSSG couple: Assay and biological significance. Methods in Enzymology, 348, 93-112.

26. Kemp, M., Go, Y. M., \& Jones, D. P. (2008). Nonequilibrium thermodynamics of thiol/disulfide redox systems: A perspective on redox systems biology. Free Radical Biology and Medicine, 44, 921-937.

27. Hutter, D. E., Till, B. G., \& Greene, J. J. (1997). Redox state changes in density-dependent regulation of proliferation. Experimental Cell Research, 232, 435-438.

28. Hoffman, A., Spetner, L. M., \& Burke, M. (2001). Cessation of cell proliferation by adjustment of cell redox potential. Journal of Theoretical Biology, 211, 403-407.

29. Aw, T. Y. (2003). Cellular redox: A modulator of intestinal epithelial cell proliferation. News in Physiological Sciences, 18, 201-204.
30. Sauer, H., \& Wartenberg, M. (2005). Reactive oxygen species as signaling molecules in cardiovascular differentiation of embryonic stem cells and tumor-induced angiogenesis. Antioxidants \& Redox Signaling, 7, 1423-1434.

31. Winterbourn, C. C., \& Hampton, M. B. (2008). Thiol chemistry and specificity in redox signaling. Free Radical Biology and Medicine, 45, 549-561.

32. Janssen-Heininger, Y. M., Mossman, B. T., Heintz, N. H., Forman, H. J., Kalyanaraman, B., Finkel, T., et al. (2008). Redoxbased regulation of signal transduction: Principles, pitfalls, and promises. Free Radical Biology and Medicine, 45, 1-17.

33. Feng, W., Liu, G., Allen, P., \& Pessah, I. (2000). Transmembrane redox sensor of ryanodine receptor complex. Journal of Biological Chemistry, 275, 35902-35907.

34. Jonas, C. R., Ziegler, T. R., Gu, L. H., \& Jones, D. P. (2002). Extracellular thiol/disulfide redox state affects proliferation rate in a human colon carcinoma (Caco2) cell line. Free Radical Biology and Medicine, 33, 1499-1506.

35. Aon, M. A., Cortassa, S., Maack, C., \& O'Rourke, B. (2007). Sequential opening of mitochondrial ion channels as a function of glutathione redox thiol status. Journal of Biological Chemistry, 282, 21889-21900.

36. May, J. M., \& Qu, Z. (2004). Nitric oxide-induced oxidant stress in endothelial cells: Amelioration by ascorbic acid. Archives of Biochemistry and Biophysics, 429, 106-113.

37. Kelly, F. J., \& Tetley, T. D. (1997). Nitrogen dioxide depletes uric acid and ascorbic acid but not glutathione from lung lining fluid. Biochemical Journal, 325, 95-99.

38. Rice, M. E., \& Russo-Menna, I. (1998). Differential compartmentalization of brain ascorbate and glutathione between neurons and glia. Neuroscience, 82, 1213-1223.

39. Jones, D., Carlson, J., Mody, V., Cai, J., Lynn, M., \& Sternberg, P. (2000). Redox state of glutathione in human plasma. Free Radical Biology and Medicine, 28, 625-635. 